Volume 10, Nomor 1, Mei 2018, pp 62-71Copyright @ 2017 Jurnal Akuntansi Maranatha, Program Studi Akuntansi, Fakultas Ekonomi, Universitas Kristen Maranatha. ISSN 20858698 | e-ISSN 2598-4977.http://journal.maranatha.edu

\title{
Pengaruh Role Stressor Terhadap Burnout dan Perbedaan Burnout Berdasarkan Gender: Studi Empiris pada Mahasiswa
}

\author{
Lina \\ Fakultas Ekonomi Program Studi Akuntansi-Univ. Pelita Harapan \\ (UPH Global Campus, Jl. MH. Thamrin Boulevard 1100, Lippo Karawaci, Banten) \\ lina.fe@uph.edu \\ Budi Hartono Kusuma \\ Fakultas Ekonomi Program Studi Manajemen-Univ. Pelita Harapan \\ (UPH Global Campus, Jl. MH. Thamrin Boulevard 1100, Lippo Karawaci, Banten) \\ budi.kusuma@uph.edu
}

\begin{abstract}
This study aims to provide empirical evidence about the positive effects of role stressors on burnout. Role stressor consists of role conflict, role ambiguity, and role overload. This study also wants to prove the difference level of burnout based on gender. The research data is the primary data that are obtained through the distribution of questionnaires to the respondents. The respondents were selected by using purposive sampling method. The specified criteria are as follows: last year students from undergradate accounting program at a private university in Tangerang. Hypothesis testing using multiple regression test and independent sample t test. The results revealed that role ambiguity and role overload have positive effect on burnout meanwhile role conflict has no effect on burnout. Differences in burnout based on gender can not be proven through the results of this study.
\end{abstract}

Keywords: Role Stressor, Burnout, Gender 


\section{Pendahuluan}

Sutarjo (2014) mengungkapkan banyak faktor yang mempengaruhi tingkat keberhasilan belajar siswa. Salah satufaktor yang mempengaruhi proses pembelajaran adalahburnoutbelajar. Burnout belajar adalah masalah yang banyak dialami oleh parapelajar yang mengakibatkan berkurangnya atau menurunnya motivasi belajar, timbulnya rasa malas yang tinggi, dan menurunnya prestasi belajar.Burnout adalah suatu kondisi mental di mana seseorang merasa dihinggapi kebosanan yang amat sangat untuk melakukan tugas rutin yang monoton dan sudah sejak lama dilakukannya.Burnout belajar berdampak sangat buruk bagi perkembangan siswa karena mempengaruhi banyak hal, baik dari segi fisik, segi mental, maupun segi psikis.Masalah burnout apabila sudah sampai pada tahap ekstrim dapat menyebabkan hal-halnegatif yang dapat membahayakan individu yang bersangkutan.

Pines et al. (1981) meneliti dan membandingkan burnout dari sejumlah profesi seperti perawat, konselor, pendidik, dan mahasiswa tingkat sarjana.Hasil penelitian menunjukkan bahwa mahasiswa tingkat sarjana memiliki skala burnout pada tingkat menengah sampai tingkat atas. Meier dan Schmeck (1985) dan Ramist (1981) mengemukakan bahwa kondisi burnout pada mahasiswa dapat mengakibatkan meningkatnya atau tingginya persentase tingkat ketidakhadiran pada setiap kelas, rendahnya motivasi untuk mengerjakan tugas-tugas yang diberikan, serta tinggginya persentase putus sekolah.

Luthans (2011) mengungkapkan bahwa burnout tidak terjadi dengan sendirinya, burnout tidak harus dihasilkan melalui masalah individu seperti karakter atau kelemahan perilaku namun lingkungan sosial memberikan kontribusi bagi timbulnya burnout.Burnout menciptakan rasa keterasingan, perasaan kehilangan kontrol, dan hubungan dengan orang lain dirasakanmenjadi berbeda. Tujuan penelitian Cordes dan Dougherty (1993) adalah untuk meneliti konstruksi burnout,mempertimbangkan bagaimana konstruksi ini telah berevolusi, dan memberikan uraian atau gambaran umum telaahliteratur mengenai anteseden dan konsekuensi dari burnout.Cordes dan Dougherty (1993) menemukan tiga anteseden dari burnout yaitu role conflict, role ambiguity, dan role overload.

Yunus dan Mahajar (2015) menyatakan bahwa adalah penting, pada tingkat individu dan juga organisasi, untuk menentukan dan mengakui tingkat work overload, role ambiguity,danrole boundaryterhadap burnout.Hal ini dibutuhkan untuk mengelola dampaknya dan untuk mencegah terjadinya eskalasi masalah.Intervensi dan perencanaan tindakan rinci harus dilakukan untuk meminimalkan terjadinya burnout.Sejumlah penelitian terdahulu menguji pengaruh role stressor terhadap burnout seperti Ermawati et al. (2014), Sukarta (2016), Pengesti (2012), Yunus dan Mahajar (2015), Abbas et al. (2012), Jamal (2005), dan Yip et al. (2008). Sukarta (2016) menguji semua komponen role stressor yaitu role conflict, role ambiguity, dan role overload sedangkan penelitian lain hanya menguji 1 atau 2 komponen role stressor. Hasil penelitian menunjukkan bahwa role stressor memiliki pengaruh terhadap burnout.

Burnout juga menarik untuk diteliti ditinjau dari perbedaan gender.Sihotang (2004) menyatakan bahwa ada dasarnya burnout dapat terjadi pada semua orang baik pria maupun wanita.Hal tersebut terjadi karena setiap manusia tentu mengalami tekanan-tekanan yang diperoleh dalam kehidupan khususnya dalam menjalani aktivitas setiap hari.Secara umum pria lebih mudah mengalami burnout daripada wanita. Hal ini dikarenakan wanita tidak mengalami tekanan seperti yang dihadapi oleh seorang pria karena bagi seorang pria 'bekerja' adalah suatu hal mutlak untuk menghidupi keluarganya, 
sedangkan bagi wanita tidaklah demikian, wanita boleh bekerja atau tidak, jadi bekerja bukanlah merupakan suatu keharusan (Gibson et al., 1987).

Berdasarkan uraian di atas, penelitian ini bertujuan untuk memberikan bukti empiris mengenai: 1)Pengaruh positif role conflictterhadap burnout. 2)Pengaruh positifrole ambiguityterhadap burnout. 3)Pengaruh positif role overload terhadap burnout. 4)Perbedaan burnout berdasarkan gender. Pada bagian selanjutnya akan dibahas mengenai kerangka teoritis yang berisi definisi konsep dasar dan pengembangan hipotesis. Metode penelitian akan diuraikan pada bagian selanjutnya diikuti dengan hasil penelitian dan pembahasan. Bagian terakhir diuraikan simpulan dan saran bagi penelitian di masa mendatang.

\section{Kerangka Teoritis dan Hipotesis}

\section{Role Stressor}

Kalbers et al. (2005) menyatakan bahwa penyebab burnout adalah role stressors yang terdiri dari role conflict, role ambiguity, dan role overload.Role conflict terjadi ketika terdapat ketidakcocokan harapan dan tuntutan yang berkaitan dengan peran yang dijalani seseorang, dimana pemenuhan harapan atas satu peran membuat pemenuhan terhadap peran lain lebih sulit. Role ambiguityakan munculjika tidak ada informasi atau pengetahuan yang dibutuhkan untukmenjalankan peran atau tugas. Role overloadterjadi ketika seseorang dibebani terlalu banyak pekerjaan dengan waktu dan kemampuan yang terbatas.

\section{Burnout}

Burnout adalah istilah yang pertama kali dikemukakan oleh Freudenberger (1974), yaitu kelelahan fisik, emosional, danmental akibat beban emosional yang kronis. Yunus dan Mahajar (2015) mendefinisikan burnout sebagai respon individu terhadap pengalaman kelelahan emosional dan interpersonal kronis yang dapat didefinisikan sebagai kombinasi dari tiga dimensi yang terdiri dari kelelahan emosional, depersonalisasi, dan pengurangan prestasi pribadi.Burnout merupakan sindrom psikologis dari kelelahan emosional, depersonalisasi, dan penurunan prestasi kerja, yang muncul di antara individu-individu yang bekerja dengan orang lain (Wiryathi, 2014).Burnout selalu lebih mungkin terjadi bila ada ketidaksesuaian antarasifat pekerjaan dengan sifat orang yang melakukan pekerjaan tersebut (Yang, 2004).Burnoutdapat menyebabkan gangguan mental dalam bentuk kegelisahan, depresi,frustasi, permusuhan atau ketakutan.Dihan dan Fatkhurohman (2012) mengungkapkan bahwa burnout memilki tiga komponen, yaitu sindrom kelelahan emosional (emotionalexhaustion), depersonalisasi (depersonalization), dan rendahnya penghargaan atas kemampuan sendiri (low personal accomplishment).Kelelahan emosional yaitu habisnya sumber emosional. Depersonalisasi yaitu sebagai perkembangan sikap negatif, sinis dan tidak mempunyai perasaan kepada orang lain. Rendahnya penghargaan diri sendiri diartikan sebagai kecenderungan untuk mengevaluasi atas kinerjanya secara negatif.

\section{Role Conflict dan Burnout}

Penelitian Ermawati et al. (2014) bertujuan untuk mengetahui pengaruh role stress terhadap kinerja auditor dengan emotional quotient sebagai variabel moderating pada Kantor Akuntan Publik di Bali. Role stress tersebut meliputi role conflict dan role ambiguity. Penelitian ini mengambil lokasi di Kantor Akuntan Publik di Bali sebanyak 8 KAP.Populasi penelitian yaitu auditor independen yang bekerja di Kantor Akuntan Publik wilayah Bali yang berjumlah 84 auditor.Sampel yang digunakan sebanyak 69 auditor.Metode pengumpulan data 
dilakukan dengan kuesioner, yang diukur menggunakan skala likert.Hasil penelitian ini menunjukkan bahwa role conflict berpengaruh signifikan terhadap kinerja auditor.Dalam penelitiannya, Sukarta (2016) menggunakan konsultan pajak pada KKP seluruh Provinsi Bali sebagai responden.Data yang digunakan adalah data primer. Data pada penelitian ini berasal dari kuesioner yang akan dibagikan kepada responden. Sampel penelitian 183 konsultan pajak.Hasil penelitian menunjukan bahwa konsultan pajak yang mengalami burnout disebabkan konsultan pajak mengalami role conflict dalam menjalankan profesinya.Pangesti (2012) melakukan penelitian mengenai pengaruh role conflict terhadap burnout dengan responden mahasiswa koass yang sedang melaksanakan praktik klinik di rumah sakit Universitas Kristen Indonesia selama 6 bulan atau lebih. Penelitian ini menunjukkan bahwa variasi variablerole conflict dapat menjelaskan variasi variabel burnout sebesar 38,9\%. Hasil penelitian ini juga mengindikasikan bahwa ketidakmampuan mahasiswa koassmenjalankan dua peran sekaligus yaitu dokter dan mahasiswa magang dan bagaimana mereka menjalin hubungan dengan orang lain yang berada di lingkungan kerjanya maka hal tersebut dapatmemberikan pengaruh positif pada terjadinyaburnout. Artinya bahwa mahasiswa koass yangmengalami konflik peran berpengaruh terhadapterjadinya burnout.

\section{$\mathrm{H}_{1}$ Role conflict berpengaruh positif terhadap burnout.}

\section{Role Ambiguity dan Burnout}

Tujuan penelitian Yunus dan Mahajar (2015) adalah untuk menyajikan temuan mengenai work overload, role ambiguity, danrole boundaryterhadap burnout.Data kuantitatif dikumpulkan melalui penyebarankuesioner kepada 2.400 perawat di rumah sakit wilayah utara Malaysia.Hasil penelitian menunjukkan bahwa role ambiguity memiliki hubungan dengan burnout dan memiliki pengaruh yang signifikan terhadap burnout.Hasil penelitian Ermawati et al. (2014) menunjukkan bahwa role ambiguity memiliki pengaruh signifikan terhadap kinerja para auditor di Kantor Akuntan Publik wilayah Bali. Abbas et al. (2012) melakukan penelitian eksploratori dengan menyelidiki peran role stressor terhadap stress dan burnout para dosen pada universitas sektor publik di negara Pakistan. Delapan puluh orang responden digunakan dalam penelitian ini.Hasil penelitian menunjukkan bahwa role ambiguity adalah salah satu role stressor yang memiliki dampak terbesar terhadap dua dimensi stres dan satu dimensi burnout.Sukarta (2016) menemukan hasil yang konsisten bahwa role ambiguity berpengaruh terhadap burnout.

\section{$\mathrm{H}_{2}$ Role ambiguity berpengaruh positif terhadap burnout.}

\section{Role Overload dan Burnout}

Jamal (2005) melakukan studi lintas budaya dengan menganalisis pengaruhrole overloadkaryawan di negara Cina dan Canada terhadap burnout. Hasil penelitian menunjukkan bahwa burnoutterbukti menjadi salah satu konsekuensi yang paling sering diteliti dan signifikan.Penelitian Yip et al. (2008) menggunakan 222 responden dari Hong Kong Institution of Engineers. Hasilnya membuktikan bahwa role overload memiliki hubungan yang kuat dengan burnout. Penelitian yang dilakukan oleh Yunus dan Mahajar (2015) menyimpulkan bahwa work overload memiliki hubungan yang kuat dengan burnout serta work overload juga berpengaruh signifikan terhadap burnout. Penelitian Sukarta (2016) menunjukkan hasil yang sama.

\section{$\mathrm{H}_{3}$ Role overload berpengaruh positif terhadap burnout.}




\section{Perbedaan Burnout Berdasarkan Gender} Penelitian Sihotang (2004) menggunakan simple random sampling untuk menentukan responden penelitian.Responden merupakan karyawan pada Departemen Sumber Daya Manusia PT Pertamina UP III Plaju.Penelitian ini membuktikan bahwa terdapat perbedaan tingkat burnoutberdasarkan jenis kelamin.Penelitian komparatif dengan menggunakan pendekatan kuantitatif dilakukan oleh Jatmiko (2016).Penelitian ini bertujuan untuk mengetahui perbedaan burnout pada siswa dan siswi kelas VIII SMPN 3 Pedan.Responden terdiri dari 88 siswa 52 siswi. Hasil penelitian menunjukkan bahwa siswa mempunyai burnout belajar yang lebih tinggi dibandingkan dengan siswi, dimana siswa memiliki mean sebesar 163,23 sedangkan siswi sebesar 155,25.

\section{$\mathbf{H}_{4}$ Terdapat perbedaan burnout antara mahasiswa dan mahasiswi.}

\section{Metode Penelitian}

\section{Data Penelitian}

Data yang digunakan dalam penelitian ini adalah data primer.Data primer tersebut didapat melalui penyebaran kuesioner kepada para responden.Responden ditentukan dengan menggunakan metode purposive sampling.Adapun kriteria yang digunakan adalah mahasiswa tahun terakhir yang berasal dari program studi $\mathrm{S} 1$ Akuntansi pada sebuah universitas swasta di wilayah Tangerang.Kuesioner yang dibagikan sesuai dengan jumlah populasi yaitu sebanyak 126.Tabel 3.1 berikut ini menunjukkan jumlah kuesioner yang didistribusikan, diterima kembali, dan digunakan dalam penelitian ini.
Tabel1

Ringkasan Kuesioner

\begin{tabular}{lc}
\hline Keterangan & Jumlah \\
\hline $\begin{array}{l}\text { Kuesioner yang } \\
\text { didistribusikan }\end{array}$ & 126 \\
$\begin{array}{l}\text { Kuesioner yang diterima } \\
\text { kembali }\end{array}$ & 120 \\
$\begin{array}{l}\text { Kuesioner yang tidak lengkap } \\
\text { diisi }\end{array}$ & 13 \\
\cline { 2 - 2 } Kuesioner yang digunakan & 107 \\
\hline
\end{tabular}

\section{Definisi Operasional Variabel dan Pengukurannya \\ Role Conflict}

Instrumen yang dikembangkan oleh Rizzo, House, dan Lirtman (1970) dan dimodifikasi oleh Murtiasri dan Ghozali (2006) serta peneliti digunakan untuk mengukur role conflict.Instrumen ini terdiri dari 5 item pernyataan.Responden dapat memilih salah satu dari skala likert 5-point.

\section{Role Ambiguity}

Untuk mengukur role ambiguity, penelitian ini menggunakan instrumen yang dikembangkan oleh Rizzo, House, dan Lirtman (1970) dan dimodifikasi oleh Murtiasri dan Ghozali (2006) serta peneliti.Instrumen terdiri dari 5 item pernyataan pada skala likert 5-point.

\section{Role Overload}

Role overload diukur dengan menggunakan instrumen yang dikembangkan oleh Beehr, Walsh dan Taber (1976) dan dimodifikasi oleh Murtiasri dan Ghozali (2006) serta peneliti. Instrumen terdiri dari 3 item pernyataanpada skala likert 5-point.

\section{Burnout}

Burnout adalah variabel dependen.Instrumen yang digunakan adalah instrumen yang dikembangkan oleh Maslach dan Jackson (1981).Setiap 
responden diminta untuk menilai tingkat burnout dengan memberikan respon terhadap 8 pernyataan.Responden memilih skala likert 5 poin.

\section{Metode Analisis Data}

\section{Uji Kualitas Data}

\section{Uji Validitas}

Salah satu uji kualitas data yang digunakan adalah uji validitas.Uji validitasditujukan untuk mengukur sah atau valid tidaknya suatu kuesioner (Ghozali, 2015). Suatu kuesioner dikatakan valid jika pertanyaan atau pernyataan pada kuesioner mampu untuk mengungkapkan sesuatu yang akandiukur oleh kuesioner tersebut. Analisis korelasi bivariate dengan menlihat pearson coefficients correlation antara masing-masing skor indikator dengan total skor konstruk digunakan untuk menguji validitas dalam penelitian ini.

\section{Uji Reliabilitas}

Uji reliabilitas adalah uji kualitas data lain yang perlu dilakukan terkait data primer. Menurut Ghozali (2015), uji reliabilitas adalah pengujian yang dilakukan untuk memastikan bahwa jawaban atau tanggapan responden terhadap pertanyaan atau pernyataan adalah konsisten dari waktu ke waktu. Untuk dapat dikatakan reliabel, suatu konstruk atau variabel harusmemiliki nilai cronbach alpha> 0.70 (Nunnaly 1994 dalam Ghozali 2015).

\section{Uji Hipotesis}

Pengujian hipotesis pertama, kedua, dan ketiga menggunakan analisis regresi berganda. Serangkaian pengujian yang dilakukan adalah uji koefisien korelasi, uji koefisien determinasi, uji $\mathrm{F}$, dan uji t.Hubungan antara variabel independen dengan variabel dependen dapat dilihat melalui uji koefisien korelasi dengan melihat nilai R. Menurut Ghozali (2015) jika nilai $\mathrm{R}$ lebih besar dari 0,5 maka hubungan antara variabel independen dengan variabel dependen adalah kuat.Uji koefisien determinasi atau uji $\mathrm{R}^{2}$ digunakan untuk menentukan seberapa besar variasi variabel dependen dapat dijelaskan oleh variasi variabel independen. Menurut Ghozali (2015), nilai koefisien determinasi berkisar antara 0 sampai 1 . Nilai $\mathrm{R}^{2}$ mendekati nol berarti kemampuan variabel independen dalam menjelaskan variasi variabel dependen sangat terbatas.Sebaliknya, jika nilai mendekati 1 berarti variabel independen memberikan hampir semua informasi yang dibutuhkan untuk memprediksi variasi variabel dependen(Ghozali 2015).Uji F digunakan untuk mengetahui apakah model regresi/empiris layak digunakan untuk penelitian. Hasil uji $\mathrm{F}$ dilihat dalam tabel ANOVA dalam kolom sig. Sebagai contoh, peneliti menggunakan tingkat signifikansi $5 \%(0,05)$, jika nilai probabilitas $<0,05$, maka dapat dikatakan model regresi/empiris layak digunakan di dalam penelitian. Uji t digunakan untuk menguji secara parsial masing-masing variabel. Jika probabilitas nilai $\mathrm{t}$ atau signifikansi $<0,05$, maka dapat dikatakan bahwa terdapat pengaruh variabel independen terhadap variabel dependen secara parsial. Nilai unstandardized coeffiecient beta digunakan untuk menunjukkan arah positif atau arah negatif.

Untuk menguji hipotesis keempat menggunakan uji independent sample t-test atau uji mann whitney. Kedua pengujian ini digunakan untuk menguji perbedaan ratarata dari kelompok yang tidak ada hubungannya.Jika data terdistribusi normal maka digunakan uji statistik inferensial parametrik yaitu ujiindependent sample $t$ test. Namun, jika data tidak terdistribusi normal maka digunakan uji statistik inferensial non parametrik yaitu ujimann whitney. Jika nilai signifikansi $<0,05$ maka terdapat perbedaan rata-rata antara 2 kelompok yang diuji. 


\section{Hasil Penelitian dan Pembahasan}

\section{Demografik Responden}

Tabel di bawah ini menampilkan demografik responden.

Tabel 2

\section{Demografik Responden}

\begin{tabular}{lr}
\hline \multicolumn{1}{c}{ Demografik } & Nilai \\
\hline Jumlah responden & 107 \\
UMUR & \\
Minimum & 17 \\
Maksimum & 22 \\
Rata-rata & 19,94 \\
$\quad$ Standar Deviasi & 0.56 \\
\hline JENIS KELAMIN & \\
$\quad$ Pria & $29(27,10 \%)$ \\
Wanita & $78(72,90 \%)$ \\
\hline
\end{tabular}

\section{Uji Kualitas Data}

\section{Uji Validitas}

Nilai $\mathrm{r}$ hitung akan diperoleh melalui uji pearson correlation. Dengan jumlah responden 107 dan jumlah variabel independen sebanyak 3 maka degree of freedom $=107-3=104$. Pada tingkat signifikansi $5 \%$ dan degree of freedom sebesar 104 maka didapat nilai $\mathrm{r}$ tabel adalah 0,191. Nilai $r$ hitung akan dibandingkan dengan nilai $r$ tabel. Jika nilai $r$ hitung lebih besar daripada nilai $r$ tabel maka dikatakan valid.Pengujian validitas dalam penelitian ini dapat dilihat pada tabel 3 berikut ini.

\section{Tabel 3}

\section{Hasil Uji Validitas}

\begin{tabular}{lccc} 
Variabel & $\begin{array}{c}\text { Rentang } \mathrm{r} \\
\text { hitung }\end{array}$ & $\begin{array}{c}\mathrm{r} \\
\text { tabe } \\
1\end{array}$ & $\begin{array}{c}\text { Keteran } \\
\text { gan }\end{array}$ \\
\hline Role & $0,564-$ & 0,19 & \\
Conflict & 0,703 & 1 & Valid \\
Role & $0,661-$ & 0,19 & \\
Ambiguity & 0,823 & 1 & Valid
\end{tabular}

\begin{tabular}{lccc} 
Role & $0,849-$ & 0,19 & \\
Overload & 0,903 & 1 & Valid \\
& $0,194-$ & 0,19 & \\
Burnout & 0,742 & 1 & Valid \\
\hline
\end{tabular}

Mengacu pada tabel di atas terlihat bahwa semua butir pernyataan adalah valid.

\section{Uji Reliabilitas}

Pengujian reliabilitas menunjukkan bahwa semua nilai cronbach's alpha di atas 0,7 sehingga dapat dikatakan bahwa tanggapan responden atas butir pernyataanadalah konsisten dari waktu ke waktu.

\section{Tabel 4}

\section{Hasil Uji Reliabilitas}

\begin{tabular}{lcc}
\hline Variabel & $\begin{array}{c}\text { Cronbach's } \\
\text { Alpha }\end{array}$ & Keterangan \\
\hline $\begin{array}{l}\text { Role } \\
\text { Conflict } \\
\text { Role }\end{array}$ & 0,750 & Reliable \\
$\begin{array}{l}\text { Ambiguity } \\
\text { Role }\end{array}$ & 0,794 & Reliable \\
$\begin{array}{l}\text { Overload } \\
\text { Burnout }\end{array}$ & 0,854 & $\begin{array}{l}\text { Reliable } \\
\text { Reliable }\end{array}$ \\
\hline
\end{tabular}

\section{Uji Hipotesis}

Hasil pengujian hipotesis pertama, kedua, dan ketiga dapat dilihat pada tabel 5.Pengujian hipotesis pertama, kedua, dan ketiga menggunakan uji regresi berganda.Hasil pengujian menunjukkan nilai $\mathrm{R}$ sebesar 0,505.Artinya terdapat hubungan yang kuat antara variabel dependen yaitu burnout dengan variabel independen yang terdiri dari role conflict, role ambiguity, dan role overload. Nilai adjusted $r$ square sebesar 0,233. Hal ini berarti variasi variabel dependen dapat dijelaskan oleh 23,3 \% variasi variabel independen, sisanya dijelaskan oleh variabel lain yang tidak dimasukkan dalam penelitian ini. Uji $\mathrm{F}$ menunjukkan nilai signifikansi sebesar 0.000 .Hal ini berarti model regresi yang digunakan adalah layak.

Hasil penelitian ini belum dapat membuktikan hipotesis pertama yang 
menyatakan bahwa role conflict memiliki pengaruh positif terhadap burnout.Hal ini dapat dilihat pada nilai signifikansi dalam tabel 5 sebesar 0.352.Penelitian ini tidak konsisten dengan penelitian yang dilakukan oleh Ermawati et al. (2014), Sukarta (2016), dan Pangesti (2012).Pada dasarnya role conflictakan timbul jika seseorang diminta untuk menjalankan beberapa peran atau tugas pada waktu yang bersamaan dimana akhirnya pemenuhan harapan atas satu peran membuat pemenuhan terhadap peran lain menjadi lebih sulit. Pada sampel mahasiswa/i yang diteliti terbukti bahwa mereka tidak merasakan adanya role conflict.Mahasiswa/i dapat menjalankan peran mereka dengan seimbang sehingga mereka tidak merasakan adanya burnout.

Penelitian ini berhasil mendukung hipotesis kedua pada tingkat signifikansi 10\%.Pada tabel 5 terlihat nilai signifikansi sebesar 0,055 dengan nilai koefisien sebesar 0,161. Role ambiguity terbukti memiliki pengaruh positif terhadap burnout. Semakin tinggi role ambiguity yang dirasakan oleh para mahasiswa maka akan semakin tinggi pula burnout yang dirasakan.Hasil ini konsisten dengan penelitian Ermawati et al. (2014), Sukarta (2016), Yunus dan Mahajar (2015), dan Abbas et al. (2012). Role ambiguity adalah kondisi dimana tidak ada informasi yang jelas atau tidak ada pengetahuan yang memadai untuk menjalankan peran atau menyelesaikan tugas.Mahasiswa/i pada sampel yang diteliti merasa ambigu terkait peran atau tugas yang harus mereka jalankan. Mereka tidak memperoleh kejelasan terkait apa yang harus dikerjakan dan bagaimana mengerjakannya. Jika kondisi ini dibiarkan berlarut-larut dalam jangka panjang maka akan mengakibatkan timbulnya burnout. Burnout tentunya akan mengakibatkan penurunan motivasi dan pada akhirnya berdampak pula terhadap penurunan prestasi belajar secara signifikan.

Hipotesis ketiga juga berhasil dibuktikan melalui hasil dari penelitian ini. Hal ini terlihat pada tabel 5, nilai signifikansi dan nilai koefisien masingmasing sebesar 0,006 dan 0,199. Role overload terbukti memiliki pengaruh positif terhadap burnout. Hasil ini konsisten dengan hasil penelitian Sukarta (2016), Yunus dan Mahajar (2015), Jamal (2005), dan Yip et al. (2008). Dalam penelitian ini, mahasiswa/i merasa beban tugas yang diberikan terlalu berat dan terlalu banyak.Role overload dapat timbul ketika beban yang diberikan terlalu berlebihan baik secara kualitas maupun kuantitas ditambah dengan kondisi tidak tersedianya waktu dan sumber daya yang memadai. Role overload yang dirasakan oleh mahasiswa/i pada akhirnya dapat mengakibatkan timbulnya burnout.

Uji normalitas menggunakan OneSample Kolmogorov-SmirnovTest menunjukkan nilai Asymp.Sig (2 tailed) sebesar 0.440. Angka ini menunjukkan data terdistribusi normal sehingga untuk menguji hipotesis keempat akan digunakan uji independent sample $t$ test. Hasil uji independent sample $t$ test menunjukkan nilai sig (2- tailed) sebesar 0.339. Karena nilai ini di atas 0,05 maka hasil penelitian ini belum dapat mendukung hipotesis keempat dengan kata lain penelitian ini belum berhasil membuktikan adanya perbedaan burnout antara mahasiswa dan mahasiswi. Hasil penelitian ini tidak konsisten dengan penelitian Sihotang (2004) dan Jatmiko (2016) yang menemukan perbedaan burnout berdasarkan gender. 


\section{Tabel 5 \\ Hasil Uji Hipotesis Pertama, Kedua, dan Ketiga}

\begin{tabular}{llll}
\hline Vaniabel & $\begin{array}{l}\text { Unstandardized } \\
\text { Coefficient }\end{array}$ & Sig. & Keterangan \\
\hline Role Conflict & 0,103 & 0,352 & $\mathrm{H}_{1}$ tidak didukung \\
Role Ambiguity & 0,161 & $0,055^{*}$ & $\mathrm{H}_{2}$ diterima \\
Role Overload & 0,199 & $0,006^{* *}$ & $\mathrm{H}_{3}$ ditenima \\
\hline
\end{tabular}

*Sigifikan pada tingkat $10 \%$

** Signifikan pada tingkat $5 \%$

\section{Simpulan dan Saran}

Penelitian ini memberikan bukti empiris bahwa role ambiguity dan role overload memiliki pengaruh positif terhadap burnout. Semakin tinggi role ambiguity dan role overload yang dirasakan oleh mahasiswa maka akan semakin tinggi pula tingkat burnout yang mereka rasakan. Penelitian ini belum berhasil membuktikan pengaruh role conflict terhadap burnout.Penelitian ini juga tidak menemukan adanya perbedaan burnout berdasarkan gender.Penelitian selanjutnya dapat menggali variabel independen lainnya yang berpotensi memiliki pengaruh terhadap burnout. Karena penelitian ini berhasil membuktikan pengaruh positif role ambiguity dan role overload terhadap burnoutmaka dapat digali variabel lain yang dapat memperkuat pengaruh positif tersebut. Responden dalam penelitian ini adalah mahasiswa program strata satu, penelitian mendatang dapat menggunakan responden yang berbeda karena sejumlah profesi lain juga rentan terhadap burnout.

\section{Daftar Pustaka}

Abbas,

SG.

A.Roger, MA.Asadullah.(2012). Impcat of Organizational Role Stressors on Faculty Stress and Burnout (An Exploratory Analysis of A Public Sector University of Pakistan).4_eme colloque international (ISEOR - AOM), 18.

Beehr, T. A, J. T. Walsh, and T. D. Taber. (1976). Relationship of Stress to Individually and Organizationally Values States: Higher Order Needs as a Moderator.Journal of Applied Psychology, Vol. 61, 41-47.

Cordes, C and T. Dougherty.(1993). A Review and Integration of Research on Job Burnout.Academy of Management Review, Vol. 18, 621-656.

Dihan, FN. dan Fatkhurohman.(2012). Mereduksi Konflik Peran dan Beban Peran pada Burnout.Diakses melalui http://eprints.unisbank.ac.id/426/1/ART IKEL-51.pdf.

Ermawati, MD., NK.Sinarwati, and E. Sujana. (2014). Pengaruh Role Stress Terhadap Kinerja Auditor dengan Emotional Quotient sebagai Variabel Moderating.e-Journal Universitas Pendidikan Ganesha, 2 (1).

Freudenberger, H. (1974). Staff Burnout.Journal of Social Issues, Vol. 30 (1), 159-165.

Ghozali, I. 2015. Aplikasi Analisis Multivariate Dengan Program IBM SPSS 23.Edisi 8. Semarang: Badan Penerbit Universitas Diponegoro.

Gibson, J.L., Ivancevich, J.M. and Donnely, J.H., JR. (1987).Manajemen Organisasi Perilaku-StrukturProses.Jakarta: Erlangga.

Jamal, M. (2005). Burnout among Canadian and Chinese Employees: A Cross Cultural Study. European Management Review, 2: 224-30.

Jatmiko, RB. (2016). Perbedaan Tingkat Burnout Belajar Siswa Laki-laki dan Perempuan Kelas VIII di SMP Negeri 
3 Pedan.E-Journal Bimbingan dan Konseling, Edisi 2, Tahun Ke-5, 11-19.

Kalbers, et al. (2005).Antecedents to Internal Auditor Burnout.Journal of Managerial Issues, Vol.17, No.1.

Luthans, Fred. (2011). Organizational Behavior: An Evidence-Based Approach. 12th Edition.Mc-Graw Hill.

Macslah, C and Susan E. Jackson.(1981). Burnout in Organizational Settings.Applied Social Psychology Annual, Vol. 5, pp. 133-153.

Meier, S.F. and Schmeck, R.R.(1985). The Burned-Out College Student: ADescriptive Profile. Journal of College Student Personal, January, 6369.

Murtiasri, Eka dan Imam Ghozali.(2006). Antesedenand Konsekuen Burnout.Simposium Nasional Akuntansi IX. Padang.

Pangesti, AA. (2012). Pengaruh Konflik Peran terhadap Terjadinya Burnout pada Mahasiswa Koass.Jurnal Penelitian dan Pengukuran Psikologi, Vol. 1, No.1.

Pines, A., Aronson, E., Kafry. (1981). Burnout: From Tedium to Personal Growth. Free Press, New York.

Ramist, L. (1981).College Student Attrition and Retention.Findings (ETS), 6, 1-4.

Rizzo, J, J House and S Lirtzman.(1970). Role Conflict and Ambiguity in Complex Organization.Administrative Science Quartely, Vol. 15, pp. 150-163. Sihotang, IM. (2004). Burnout Pada Karyawan Ditinjau Dari Persepsi Terhadap Lingkungan Kerja Psikologis Dan Jenis Kelamin.Jurnal PSYCHE, Vol. 1, No. 1, 9-17.

Sukarta, MAP. (2016). Pengaruh Role Conflict, Role Ambiguity, Role Overload,dan Job Insecurity pada Burnout Konsultan Pajak di Kantor Konsultan Pajak Se-provinsi Bali. Tesis Program Pasca Sarjana Universitas Udayana Denpasar.

Sutarjo, IE., Dewi Arum WMP, NK Suarni. (2014). Efektivitas Teori Behavioral
Teknik Relaksasi dan Brain Gym Untuk Menurunkan Burnout Belajar pada Siswa Kelas VIII SMP Laboratorium Undiksha Singaraja Tahun Pelajaran 2013/2014.e-journal Undiksa Jurusan Bimbingan Konseling, Volume 2, No 1.

Wiryathi, NM., NK. Rasmini, MG Wirakusuma. (2014). Pengaruh Role Stressors pada Burnout Auditor dengan Kecerdasan Emosional sebagai Variabel Pemoderasi.E-Jurnal Ekonomi dan Bisnis Universitas Udayana, 3.5 ,227-244.

Yang, HJ.(2004). Factors Affecting Student Burnout and Academic Achievement in Multiple Enrollment Programs in Taiwan's Technical-Vocational Colleges.International Journal of Educational Development, 24, 283301.

Yip, Y., Rowlinson, S., \& Siu, O. L. (2008). Coping Strategies as Moderators in The Relationship Between Role Overload and Burnout. Construction Management and Economics, 26(8), 871-882.

Yunus, Jasmani Binti Mohd. and Abdul Jumaat Bin Mahajar. (2015). Work Overload, Role Ambiguity and Role Boundary and its Effect on Burnout among Nurses of Public Hospitals in Malaysia.International Journal of Research in Humanities and Social Studies, Volume 2, Issue 10, 18-25. 